\title{
Muisneñas construyendo y reconstruyendo su espacio en la isla de Muisne a partir del terremoto del 16 de abril de 2016
}

\section{WOMEN BUILDING AND REBUILDING THEIR SPACE ON MUISNE ISLAND AFTER THE EARTHQUAKE OF APRIL 16, 2016}

MUISNEÑAS CONSTRUINDO E RECONSTRUINDO SEU ESPAÇO NA ILHA DE MUISNE A PARTIR DO TERREMOTO DE 16 DE ABRIL DE 2016
Para citar este artículo: Jurado Velastegui, E. (2020). Muisneñas construyendo y reconstruyendo su espacio en la isla de Muisne a partir del terremoto del 16 de abril de 2016. Perspectiva Geográfica, 25(2) 80-101. https://doi.org/10.19053/01233769.10297
Recepción:

16 de noviembre de 2019

Evaluación:

14 de abril de 2020

Aprobación:

24 de julio de 2020

\section{Resumen}

El presente artículo ha sido elaborado a partir del relato de una mujer conchera afroecuatoriana de la isla de Muisne y explora la experiencia de sobrevivir al terremoto de 7,8 grados en la escala de Richter del 16 de abril de 2016, así como las dinámicas que dieron paso a la construcción y reconstrucción de sus espacios. A través de un respaldo teórico conjugado con descripciones periodísticas, se indaga

1 Licenciada en Periodismo por la Universidad de las Américas, Ecuador. Diplomada en Teoría Política y Gestión Pública por la Universidad Miguel de Cervantes, Chile. Maestrante de Género y Desarrollo de la Facultad Latinoamericana de Ciencias Sociales, Ecuador. Correo: estefyjurado@gmail.com. Orcid: https://orcid.org/0000-0002-9175-5737. 
sobre el contexto previo al evento natural que dejó en evidencia situaciones de pobreza, violencia, falta de institucionalidad y carencias en la gestión riesgos por parte del Estado.

En el caso particular de las muisneñas, las desigualdades de género se agudizaron en esta conexión entre el abandono previo, el desastre y los nuevos paisajes geopolíticos del desalojo. Sin embargo, después del desastre surgieron estrategias y procesos de resistencia y de apropiación de los espacios de las mujeres que significaron un replanteamiento en sus condiciones de vida.

Palabras clave: territorio, Muisne, manglar, terremoto, mujeres, desastre, pobreza, desalojo, resistencia, geografía feminista.

\section{Abstract}

This article relies on the story of an Afro-Ecuadorian female mollusk collector from Muisne Island. It explores the experience of surviving the 7.8 Richter scale earthquake of April 16, 2016, and the dynamics that gave way to building and rebuilding spaces. Within a theoretical framework combined with journalistic descriptions, it looks into the context before the natural disaster, which revealed poverty, violence, absence of institutions, and deficiencies in risk management by the state. In the particular case of Muisne women, gender inequalities became more acute in this convergence between previous abandonment, the disaster, and the new geopolitical landscapes of eviction. However, the disaster gave rise to strategies and processes of resistance and appropriation of spaces by women, which meant rethinking their living conditions.

Keywords: Territory, Muisne, mangrove, earthquake, women, disaster, poverty, eviction, resistance, feminist geography.

\section{Resumo}

O presente artigo tem sido preparado a partir do relato de uma mulher conchera afroequatoriana da ilha de Muisne e explora a experiência de sobreviver ao terremoto de 7,8 graus na escala Richter de 16 de abril de 2016, bem como as dinâmicas que deram lugar à construção e reconstrução dos seus espaços. Por meio de um suporte teórico conjugado com descrições jornalísticas, indaga-se sobre o contexto anterior ao acontecimento natural que revelou situações de pobreza, violência, falta de institucionalidade e deficiências na gestão dos riscos por parte do Estado. 
No caso particular das Muisneñas, as desigualdades de gênero tornaram-se mais agudas nessa conexão entre o abandono anterior, o desastre e os novos cenários geopolíticos do desalojamento. Porém, após o desastre, surgiram estratégias e processos de resistência e apropriação dos espaços das mulheres, o que significou um repensar de suas condições de vida.

Palavras-chave: território, Muisne, mangue, terremoto, mulheres, desastre, pobreza, desalojamento, resistência, geografia feminista.

\section{Introducción}

El 16 de abril de 2016 a las 18:50 se produjo en Ecuador un terremoto de 7,8 grados en la escala de Richter que devastó las provincias costeras de Manabí y Esmeraldas. Según cifras oficiales, las pérdidas humanas ascendieron a 668 , los heridos fueron 6.274, hubo 80.000 personas desplazadas y 29.775 albergadas, según datos de la Secretaría de Planificación y Desarrollo y la Comisión Económica para América Latina y el Caribe (2016). Así mismo, la evaluación realizada por estas entidades señaló que los daños materiales ascenderían a una cifra base de $\$ 3.344$ millones.

El país atravesó por una de las más grandes pérdidas humanas y materiales ocasionadas por un desastre natural que dejó en evidencia situaciones de pobreza, violencia, falta de institucionalidad e incapacidad de gestionar riesgos por parte del Estado. Una de las localidades afectadas fue el cantón Muisne, ubicado en la provincia de Esmeraldas, donde no se registraron víctimas mortales, pero sí daños materiales en el $85 \%$ de la infraestructura de la isla. El gobierno del entonces presidente Rafael Correa declaró a la isla en situación de riesgo y se ordenó el desalojo de la población hacia el continente.
La presente investigación se desarrolla en esta población en particular, con una situación social, económica y geopolítica que ya era considerada de riesgo antes del terremoto. Según el Atlas de las desigualdades socio-económicas del Ecuador (Secretaría Nacional de Planificación y Desarrollo, 2013), el 98,3\% de la población en el cantón es considerada pobre por presentar necesidades básicas insatisfechas (NBI). En el caso particular de las mujeres muisneñas, las desigualdades de género también se agudizaron en esta conexión entre el abandono previo, el desastre y los nuevos paisajes geopolíticos del desalojo. Surgieron también procesos de resistencia y de apropiación, de construcción y reconstrucción de espacios que podrían significar un replanteamiento en las condiciones de vida y sus relaciones de género.

Este artículo se ha elaborado a partir del relato de una mujer afroecuatoriana de la isla de Muisne, llevado a cabo entre el 22 de abril de 2016 hasta el 31 de octubre de 2018. Cada encuentro con la participante se realizó dentro de sus espacios más personales, ya sea en el calor de la estufa con un arroz recién cocido o dentro del fango durante el ejercicio de conchar entre mujeres. A través de la preparación y la recolección de alimentos, ella ha creado sus mapas de vida y de la de los suyos. En 
ese sentido, metodológicamente se han empleado dos técnicas alineadas a la geografía feminista: los mapas de relieves de la experiencia propuestos por Rodó de Zárate (2014), que consisten en una forma visual de mostrar las experiencias interseccionales en los espacios, ya que al graficar las variables es posible materializar la manera en que mutuamente se constituyen (p. 3); y la deriva propuesta por Malo (2004), que señala que

[...] en lugar de sentarnos a hablar de manera estática, elegimos movernos, recorrer los circuitos de la precarización urbana como tantas veces nos toca hacer en nuestro cotidiano, pero esta vez no hacerlo en solitario, sino juntas, contándonos unas a otras la materialidad de nuestras precariedades, rastreando sus marcas en el espacio metropolitano, encontrando e interpelando a otros cualquiera (p. 84).

Así mismo, el análisis socioeconómico del territorio se complementa con investigación cuantitativa para la medición de indicadores nacionales e internacionales que dan cuenta del contexto previo de abandono y pobreza.

\section{Radiografía de Muisne: breve} recorrido por la isla antes del

\section{terremoto}

15 de abril del 2016, un día antes del terremoto. Las calles de Muisne tampoco estaban pavimentadas, algunas tenían adoquines en muy mal estado que incluso fungían de herramientas para espantar a los cerdos que deambulaban por la isla en busca de comida. La isla, con una temperatura de 30 gra- dos al medio día, no tenía alcantarillado, agua potable ni un hospital básico. Algunos niños y niñas estaban en la escuela mientras otros, los que habían desertado de la educación o aún no cumplían la edad para ingresar al sistema, jugaban con la pelota sobre el polvo seco y caliente. Las mujeres habían regresado de recolectar conchas y preparaban el almuerzo. Algunos hombres jugaban barajas y otros pescaban en altamar. El empleo formal no es una constante por esta zona.

17 de abril de 2016, un día después del terremoto. El panorama había empeorado, se sumaba la tragedia de las casas destruidas, refrigeradoras y cocinas atrapadas en el fango del estuario, gente acampando en la calle para que la delincuencia no se llevara las pocas prendas o muebles que se habían salvado.

\subsection{Cifras e indicadores}

El terremoto develó un sistema fallido de funcionamiento social. Según el Atlas de las desigualdades socio-económicas del Ecuador ${ }^{2}$ (Secretaría Nacional de Planificación y Desarrollo, 2013), el 98,3\% de la población de Muisne es considerada pobre por necesidades básicas insatisfechas (NBI); el embarazo adolescente es del 25,44\% y tan solo el 6\% de hogares cuenta con agua potable pública; el 30\% de los hogares están en condiciones de hacinamiento y las viviendas con características físicas inadecuadas corresponde al 95,25\%.

2 Este dato se obtiene a corte del año 2013 por la Secretaría de Planificación y Desarrollo. Se prevé que el próximo censo de población y vivienda se realice en todo el territorio ecuatoriano para el mes de noviembre del 2020. 


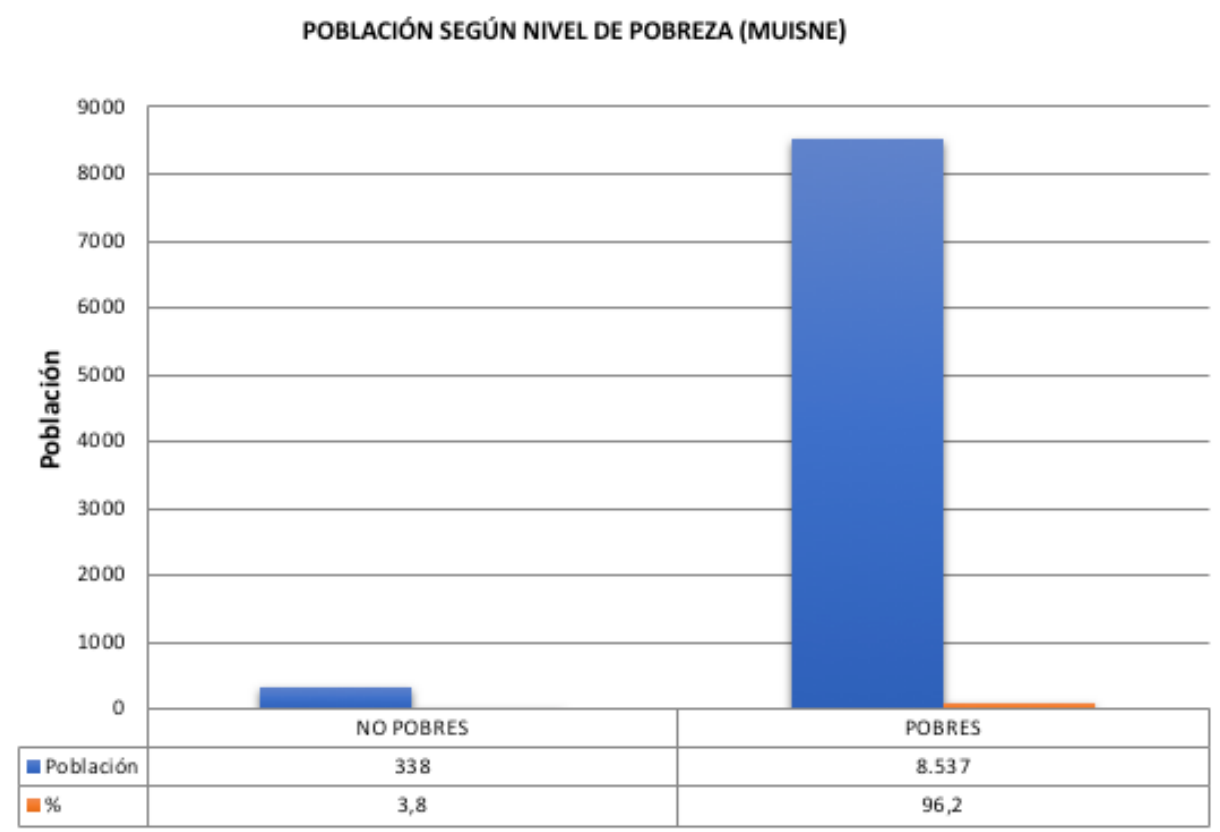

Tabla 1. Población de Muisne según el nivel de pobreza

Fuente: elaboración propia a partir del censo del año 2010 (Instituto Nacional de Estadística y Censos [INEC], 2010).

Para el caso particular de las mujeres muisneñas, quienes representan el $46,1 \%$ de la población de ese territorio, las desigualdades de género también se han agudizado en esta conexión entre el abandono previo y el desastre: el $58 \%$ de las mujeres en la isla han sufrido algún tipo de violencia por su condición de género. El 38,6\% de las mujeres se encuentran unidas a su pareja, en contraposición al 15,5\% que están casadas, lo que ha significado un inconveniente a la hora de demandar derechos y obligaciones propios de la sociedad conyugal y ocasiona problemas con relación a la tenencia de propiedades, la manutención de los hijos y las herencias.

Respecto a la educación, las mujeres tienen una mayor escolaridad que los hombres, con una media de 8,9 años frente al 8,3. Sin embargo, según la Comisión Económica para América Latina y el Caribe (Cepal, 2012), las mujeres en Latinoamérica y el Caribe son mejor educadas que los hombres, pero están peor pagadas. Se señala que, pese a tener un mayor número de años de educación, los empleos a los que acceden son mal remunerados.

En cuanto a las actividades económicas de las mujeres en Muisne, no existe información oficial levantada. Sin embargo, de acuerdo con las entrevistas ${ }^{3}$ realizadas, se aprecia que en su mayoría se han dedicado a la recolección de conchas, la preparación de alimentos, la venta

3 Entrevistas realizadas en los meses de abril, mayo, junio y julio de 2016. 
por catálogo y el servicio de limpieza en las grandes cadenas hoteleras de Mompiche. Una de las principales desventajas encontradas en las mujeres de Muisne con relación a los hombres al momento de la generación de ingresos es la falta de espacios legalmente constituidos como propios, lo que ocasiona una constante disputa en las relaciones. Deere y León (2002) ponen en evidencia la falta de acceso a la tierra (bien material) de las mujeres en América Latina, lo cual aumenta la brecha de género en materia económica. En otras palabras, queda clara la limitación que tienen las mujeres para ser propietarias de las tierras.

\subsection{La aplicación de políticas públicas: el decreto que obliga a abandonar la isla}

Según la Secretaría de Riesgos, el 85\% de la infraestructura de la isla de Muisne era vulnerable a inundaciones por oleajes y aguajes, es por ello que, acogiéndose al informe técnico realizado por la Dirección de Análisis de Riesgos del 21 de junio de 2016, el expresidente Rafael Correa declaró a la isla de Muisne como zona de alto riesgo mediante Resolución n ${ }^{\circ}$ SGR-073-2016, prohibió los asentamientos humanos y dispuso al gobernador de la provincia de Esmeraldas y al alcalde de Muisne para que dentro del ámbito de sus competencias realicen acciones para acatar la normativa $^{4}$ (Secretaría de Gestión de Riesgos, 2016).

Ante la Resolución NoSGR-073-2016, el expresidente de la república señaló: "Pero vino el terremoto, con el terremoto se evidenció que la isla de Muisne es de alto riesgo, es sedimento, no es suelo firme, es suelo muy bajo, viene un tsunami y arrasa la isla. Entonces no podemos hacer un puente para que la gente vaya a vivir a zona de riesgo, de
La materialización de la resolución consistió en el desalojo de todas las entidades públicas de la isla, incluidas las escuelas y el centro médico, y el traslado a campamentos de más de mil familias mientras se coordinaba el nuevo asentamiento de Muisne en 14 hectáreas de la parte continental vía al recinto El Bunche que, según la Secretaría de Gestión de Riesgos, era una zona segura. Esta decisión gubernamental dividió a la población en dos sectores: los que acataron la orden pese a la carga simbólica que significaba dejar su hogar y quienes se resistieron pese a todo.

La administración de la población en un sistema global ha tenido cabida en el sistema Estado-nación, que para Sassen (2006) es el ensamblaje entre territorio, autoridad y derechos, y se aprecia en la situación de las mujeres de Muisne. La importancia de la articulación del género para el análisis junto con otras categorías (Arroyo \& Valladares, 2005 , p. 399), trasladado al campo de la asistencia humanitaria, supone la diferencia entre la vida y la muerte, ya que en situaciones críticas en las que tienen lugar movilizaciones, desplazamientos forzados o refugio la suma de violaciones a los derechos humanos va en aumento. Dado que no se han elaborado protocolos de apoyo con enfoque de género en situaciones de desastre, las mujeres viven la experiencia de la devastación, la construcción

hecho, cuando esté ese puente y no estemos nosotros en el gobierno verán que nadie va a controlar que todo el mundo se instale en Muisne y tendremos ahí una bomba de tiempo. Por eso dije, vamos a hacer un puente solo para tricimotos, para ciclistas y un puente peatonal porque la idea es que esa isla de Muisne quede como sitio turístico, no como vivienda permanente. Por supuesto, no vamos a poder reubicar al que no quiere moverse" (Tele Ciudadana, 2016). 
y la reconstrucción de una manera diferente a los hombres.

\section{Discusiones teóricas sobre}

\section{Muisne en el contexto del}

\section{terremoto del 16 de abril de 2016}

Una de las localidades más afectadas por el terremoto fue la cabecera cantonal de Muisne en la provincia de Esmeraldas, que registró un $85 \%$ de daños en la infraestructura ubicada sobre el estuario o cercana al mar. Por tal motivo, mediante Resolución n SGR-073-2016 de carácter obligatorio, durante la presidencia de Rafael Correa se declaró a este territorio como zona de alto riesgo con probabilidades de ser inundada por tsunamis y se procedió al desalojo de la isla con la fuerza pública ${ }^{5}$.

Este acontecimiento natural no solo incrementó la vulnerabilidad de las poblaciones que se encontraban en el epicentro, sino que develó toda una situación de riesgo ante desastres por la carencia de servicios básicos, educación y salud de calidad, seguridad e infraestructura, agudizadas por condiciones de clase, raza y sexo.

Se teoriza entonces que el desastre surge como resultado del encuentro entre una determinada amenaza y una población vulnerable en condiciones de riesgo, que actúan como detonantes de situaciones preexistentes y llevan hacia cambios sociales y culturales (García Acosta, 2004, p. 50). Para Beck (1998), el reparto de los riesgos guarda relación con el reparto de las riquezas porque se sigue el

5 El 8 de febrero de 2019, mediante Resolución n SNGRE-011-2019, el Servicio Nacional de Gestión de Riesgos y Emergencias (SNGRE) derogó la Resolución n SGR-0732016 que declaraba a Muisne como zona de riesgo. mismo esquema de clase pero al revés, ya que "las riquezas se acumulan arriba, los riesgos abajo. Por tanto, los riesgos parecen fortalecer y no suprimir la sociedad de clases" (p. 41).

En diálogo con Foucault (1998), Castro-Gómez (2000), Cabezas y Berná (2013), Mbembe (2011) y Agamben (1998), se sugiere que el terremoto de Ecuador tuvo lugar en un contexto globalizado que trajo consigo configuraciones de las relaciones de poder y la producción de nuevas diferencias a través del manejo de la población: con la biopolítica, como el intento de "someter la vida entera al control absoluto del hombre bajo la guía segura del conocimiento" (Castro-Gómez, 2000, p. 88) y como estrategias usadas por el Estado para controlar (regular) los cuerpos y las poblaciones (Foucault, 1998); con la nuda vida, como la vida expuesta al poder soberano de la muerte, que sin ningún tipo de vestido se reduce a una condición biológica absolutamente manipulable en la que el Estado moderno saca a la luz "el vínculo secreto que une el poder con la vida" (Agamben, 1998, p. 16); con la necropolítica, que expone la manera en que para el poder unas vidas tienen más valor que otras y configura sujetos desechables, "contribuyendo a aniquilar la integridad moral de las poblaciones" (Mbembe, 2011, p. 15).

Los discursos analíticos tejidos alrededor del manejo de las poblaciones en situación posdesastre por parte del Estado mantienen la perspectiva de mirar hacia "los otros", "los diferentes" como objetos de estudio no participantes que deben cumplir órdenes, como la del desalojo en este caso específico. En La doctrina del shock (Klein, 2008) se sostiene que un desastre natural, social e incluso de mercado lleva a la población a un estado de shock colectivo tal que es utilizado como recurso 
o herramienta para desorientar a los individuos, logrando así privaciones sensoriales que impiden visualizar medidas que se toman en otros ámbitos distintos al de salvarse de la crisis (p. 23). Es decir, tienen lugar reformas, sobre todo económicas, que modifican el paisaje y que en otra situación no hubiesen sido posibles.

Desde las dinámicas de género en situaciones posdesastre, Horton (2015) señala que el impacto de las experiencias marca de diferente manera a los segmentos de la población y afirma que las políticas empleadas por el Estado han descuidado la mirada de género. Para explicar mejor estos cambios, Magaña Frade et al. (2010) proponen el concepto de subjetividad femenina terremoteada como el impacto subjetivo por el que pasan las mujeres afectadas por desastres naturales y la manera en que se manifiestan sus reacciones. Autores como Horton (2015), Magaña Frade et al. (2010) y Luft (2009) coinciden en que, pese a las implicaciones estructurales (violencia, desigualdades, trabajo no reconocido) que devela un desastre natural, existe la posibilidad de organización, de reconfiguración de relaciones sociales y de reconstrucción justa de los espacios.

Los espacios como principal escenario de expresión social y cultural construyen lugares significativos que marcan simbólicamente el territorio y generan y transmiten memoria colectiva (Borja, 2003, p. 4). Según Massey (Bernal, 1998), los espacios y los lugares, así como el sentido que se tiene de ellos, son estructurados según una matriz de género que varía de acuerdo con la cultura y el tiempo y reflejan la forma en que el género se construye y configura las relaciones sociales.

McDowell (2000), usando la categoría analítica geográfica y espacial, da cuenta de cómo los espa- cios construyen identidades y relaciones sociales y cómo las jerarquías pueden tener formas específicas en lugares específicos. En este contexto, es importante tomar en cuenta la manera en que los cuerpos pueden volverse espacios que localizan al individuo (p. 60).

Pero ¿por qué tienen tanta importancia los cuerpos en la construcción de los espacios? En ellos se sitúan todas las relaciones que hacen posible la interacción social y la construcción de discursos a distintas escalas. A través del acto político de construir, las mujeres han tenido la posibilidad de recrear sus propias cartografías con las marcas de la memoria y del cuerpo como un territorio con historia, memoria y conocimientos (Gómez, 2012), convirtiéndose en un espacio de lucha que reconoce emociones y subjetividades para también reconstruir las relaciones de género.

Cabe mencionar que los cuerpos en cuestión están atravesados por categorías, en ellos se interconectan simultáneamente sexo, raza, género, clase y sexualidad, entre otras, para visualizar las relaciones jerárquicas de poder. Este concepto crítico de utilidad teórica y política llamado interseccionalidad evidencia cómo la convergencia de estas categorías en varias dimensiones de la vida social construye mecanismos de desigualdad social. El censo del 2010 señala que la provincia de Esmeraldas cuenta con el asentamiento más alto de población afrodescendiente del país, en donde el $40 \%$ se autoidentifica como negra, 46,4\% como mestiza, el $10,3 \%$ como blanca y un $3,3 \%$ como indígena. Por lo tanto, la experiencia de un desastre natural para las mujeres de Muisne es vivida de acuerdo con las particularidades dadas por la intersección entre género, raza, etnia y territorio. 


\section{Nachita Bautista y el}

\section{manglar: de los espacios que construyen identidades y relaciones sociales}

Nachita Bautista es una mujer negra de 43 años, madre soltera de siete hijos y conchera desde la adolescencia. A los 16 años empezó a recolectar conchas negras de los manglares de la isla de Muisne para generar su propio dinero, pero también como un momento para compartir con otras mujeres, escuchar historias y soltar una que otra confidencia. Junto a sus primas, recorría las telarañas de ramas y lodo para encontrar este preciado molusco que después sería vendido a los restaurantes de Atacames, Tonsupa, Casa Blanca y Esmeraldas para ser consumido, en su mayoría, por turistas de la sierra ecuatoriana.

Con botas de plástico marca Venus, un pantalón de tela gruesa y blusa de manga larga para protegerse de los mosquitos, sale a conchar todos los días en una canoa junto a su hermano menor (el encargado de remar) y sus vecinas. Él las deja en uno de los manglares y se dirige a otro esperando tener suerte porque la tala por parte de las camaroneras limita cada vez más su trabajo. Ella baja de la canoa y con mucha facilidad se agarra de un palo de mangle; se mueve entre las ramas con la destreza que solo tienen las personas que han convivido con la naturaleza desde los primeros años de vida. No hay un manual que le indique en dónde encontrará las conchas más grandes, pero la experiencia la ha hecho desarrollar habilidades extraordinarias y de una vez mete su mano en el lodo, hace un movimiento circular y saca una concha negra y grande que en pocas horas será servida en un ceviche.
Nachita sabe, por ejemplo, que las conchas están pegadas a las raíces del mangle, que las más pequeñas siempre se devuelven al sitio en el que fueron encontradas para que terminen su ciclo de crecimiento. Conoce también el cuidado con el que se debe trabajar en esto porque dentro del fango se puede encontrar serpientes y peces con espinas externas tan grandes y filudas que se entierran entre las uñas y la piel, los dedos y cualquier parte de la mano: los gajes del oficio, dice ella cuando menciona que una de sus compañeras perdió un dedo luego de que la pólvora ${ }^{6}$ no cumpliera la función de sanarla.

Las mujeres concheras reciben $\$ 10$ por cada cien conchas y para conseguirlas deben emplear entre dos a cuatro horas de su día en el manglar, cubiertas de fango, con altas temperaturas, expuestas a la picadura de serpientes y mosquitos y a otros peligros que llegaron con la industrialización: las camaroneras le han ido ganando espacio al manglar y se han apropiado de la principal fuente de empleo de las mujeres de Muisne y del espacio de complicidad en el que comparten sus historias más íntimas.

Ese pedacito de manglar que se ve ahí es bueno, salen conchas grandes y llenaríamos el saco en máximo media hora, pero no podemos entrar porque las camaroneras los prohíben. Ahí están los tigres, así les decimos a los perros amaestrados que cuidan el manglar de las camaroneras, nosotros quisimos darles carne con veneno, pero ellos saben que no pueden comer nada de nadie, solo de sus dueños. Un

6 Entre las concheras existe la creencia de que si un pez clava sus espinas en los dedos al momento de meter la mano en el fango la manera de curarse es con pólvora. Así lo aprendieron desde sus primeros años, y la carencia de servicios de salud las mantiene realizando esta práctica que ya le ha costado la amputación de dedos a varias de ellas. 
compañero nuestro quiso conchar ahí y los tigres lo mataron (Entrevista con Nachita, agosto de 2017).

\subsection{El terremoto}

El 16 de abril de 2016 Nachita había conchado temprano, después preparó el almuerzo para su familia, miraron televisión en horas de la tarde, conversó con sus vecinas desde la puerta de su casa de madera construida sobre el estuario y decidió caminar hacia otro barrio justo antes de que empezara el movimiento.

El día del terremoto fue algo horroroso para mí [...]. Durísimo para mí, me desesperaba, yo gritaba de pensar que mis hijos se iban a morir en mi presencia, yo dije "los voy a ver morir" a mis hijos y me pareció que no iba a poder soportar. Quería que, si Dios me iba a matar, me matara de un instante con todos ellos porque yo no quería verlos morir [...]. Cuando ya pasó un poco vine corriendo acá a mirar a mi papá y a mi hija. Mi papi dice que apenas sintió el primer movimiento se bajó y mi hija ya estaba abajo. Ya se me había caído la casa, como era construido en el agua, en sí es parte de la orilla, llegó ya el agua, todo se me destruyó, se me cayó (Entrevista con Nachita, abril de 2016).

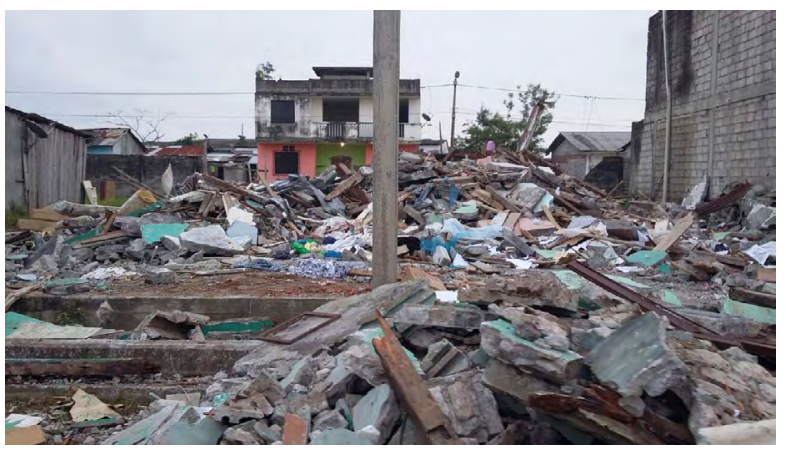

Figura 1. Escombros de parte de la casa de Nachita en abril de 2016

Fuente: Archivo personal de la autora.
La misma noche del terremoto Nachita agarró a sus hijos, una maleta con sábanas (fue lo único material que se salvó) y se marchó al patio de la escuela en Palma Junta, en una población cercana. Allí se acomodaron como pudieron junto a treinta personas más que huyeron por temor a una réplica o un tsunami. Pensaron que su estancia allí sería temporal, pero se quedaron durante seis meses antes de ser traslados a un albergue administrado por el Ministerio de Bienestar Económico y Social (MIESS) y vigilado por personal de las Fuerzas Armadas Ecuatorianas.

Yo no superaba la experiencia, para mis hijos fue muy fuerte porque ellos no comían... sufrimos mucho, yo no dormía porque dormir en una carpa es algo que a uno se le hace como un trauma porque es una montaña donde hicieron el albergue [...], y yo en mi mente me imaginaba que de repente una culebra o alguien se entre a violar a mis hijos, fue algo traumante (Entrevista con Nachita, abril de 2016).

Vivir con el miedo de ser víctimas de una violación o de una picadura de serpiente, las normas impuestas por los militares (totalmente distintas al modo de vida de los isleños) dentro de los albergues y la comida enlatada, producto de las donaciones, ocasionaron tal situación de estrés en Nachita y sus hijos que dejaron de comer. Ella sabía que extrañaban el arroz con concha de su mamá, el ceviche y el arroz blanco, pero con su sazón. Todos los días le pedían salir del albergue y regresar al espacio en donde estaba su casa, así fuera para vivir en construcciones levantadas con palos y plásticos como lo hicieron varios de sus vecinos, pero ella se resistió porque desde el MIESS les habían advertido que si salían antes del año no podrían ser acreedores a las viviendas que construía el Gobierno. 
Dos habitaciones de concreto, un baño, una cocina, ventanas cuadradas, sin espacio para mirar lo que sucede fuera: la nueva casa de Nachita, entregada por el Ministerio de Desarrollo Urbano y Vivienda (Miduvi) ${ }^{7}$, era abismalmente opuesta a su anterior hogar; ya no podían escuchar el mar, conversar con las vecinas o salir a conchar cuando quisiera. La nueva construcción, que finalmente estaba a su nombre, se ubica a kilómetros de la isla de Muisne, en el continente, por lo que caminar dejó de ser su medio de transporte y el de su familia. El uso de una tricimoto al costo de $\$ 1$ por persona en cada carrera se hizo imprescindible.

Ella tenía sentimientos encontrados, por primera vez era acreedora de un título de propiedad, sin embargo, se alejaba mucho del paisaje al que ella y sus hijos estaban acostumbrados. Nunca nadie les preguntó cómo eran sus casas antes, cómo podrían combinar la arquitectura moderna con aquellas que habían sido construidas por sus propias manos sobre el agua. Al fin tenía un inodoro funcional, un lavabo en el baño, piso de baldosa y hasta cocina de inducción, pero nada de eso le devolvía la sonrisa porque extrañaba el mar, la isla, su espacio.

$7 \quad$ Según el Acuerdo Ministerial 016-17, firmado en febrero del 2017, los damnificados del terremoto del año 2016 que fueren beneficiarios con viviendas sociales valoradas en \$10.000 tienen la obligación de realizar un copago correspondiente al 10\% después del segundo año de recepción. Según el artículo 3 del mencionado acuerdo, en caso de incumplimiento o retraso por más de seis meses consecutivos se reserva el derecho de reversión del incentivo.

\subsection{Quiero a la isla porque ahí me hicieron: consideraciones sobre el espacio y asumirse dentro de él como sujeto político}

Comprender la organización espacial de la sociedad, por tanto, es crucial. Es central para nuestra comprensión de las maneras como funcionan los procesos sociales; para nuestra conceptualización de alguno de aquellos procesos, probablemente, y para nuestra capacidad para actuar sobre ellos políticamente, con certeza.

Doreen Massey, "New Directions in Space"

"Es algo duro porque uno ya está acostumbrado, uno nació [...], aquí me hicieron, aquí me he criado, aquí me estoy envejeciendo y es algo duro tener que irse", responde Nachita ante la pregunta de cómo se sintió cuando tuvo que salir de la isla. Para entender lo significativo que resulta para ella volver al lugar geográfico en el que se encontraba su antigua casa, pese a tener una nueva con "aparentes" mejores condiciones, se parte de Massey (1999) y su conceptualización del espacio como un medio en el que se reproducen las relaciones sociales. Así pues, esta autora propone que el espacio está constituido y es producto de interrelaciones que van desde lo global hasta lo más íntimo, y que es en esta esfera donde se posibilita la existencia de la multiplicidad en donde coexisten varias voces y trayectorias. Afirma que "si el espacio es en efecto producto de interrelaciones, entonces debe ser una cualidad de la existencia de la pluralidad. La multiplicidad y el espacio son co-constitutivos" (p. 105). 
Para Blanco, los espacios están dotados de valor y de vida una vez que son percibidos a través de los sentidos, la experiencia y las ideas, donde tienen lugar procesos de producción y reproducción social (Blanco, 2007, p. 39). Regresamos también a McDowell (2000), que da cuenta de cómo los espacios construyen identidades y relaciones sociales, $\mathrm{y}$, en este contexto, es importante tomar en cuenta la manera en que los cuerpos pueden volverse espacios que localizan al individuo. La discusión desde la geografía feminista se apoya en Castillo (2011), quien parte de la experiencia del terremoto en Chile que tuvo lugar en el año 2010 para discutir la importancia de los espacios y los territorios en la comprensión de las dinámicas pre y posdesastre. La autora sostiene que es en el espacio donde se desarrollan relaciones sociales, políticas, económicas y culturales que constituyen al territorio como un espacio "vivo e inacabado" que está en transformación. Apoyada en este marco analítico, señala la posibilidad de identificar "formas concretas en que espacio y exclusión/ resistencia interactúan e impactan el uno sobre el otro" (p. 4).

Para Rodó de Zárate (2014), las relaciones de poder y la reproducción de desigualdades se hacen visibles a través de la producción de los espacios y dan cuenta de cómo las categorías que se interseccionan no son estáticas y dependen de construcciones espaciales, temporales e históricas. Sin embargo, Castillo (2011, citando a Lefebvre) identifica la conexión de los momentos de producción del espacio con las formas concretas en que "las prácticas espaciales de los y las actores sociales configuran proyectos territoriales de desarrollo que surgen como respuesta - y en oposición - a los modelos hegemónicos y excluyentes" (p. 7). Además, señala la importancia de que los actores tomen protago- nismo de sus realidades para fortalecer los procesos de empoderamiento desde un reconocimiento individual para pasar a uno colectivo.

Nachita dice que su hogar/espacio se encuentra en la isla de Muisne, donde parió a sus siete hijos e hijas, donde ayudó a nacer a sus nietos, donde vio a la policía llevarse preso a su marido, donde se inmiscuyó en la organización de mujeres concheras, donde militó para no desalojar su tierra. Su espacio, donde se sentía segura pese al complejo escenario social y político de la isla, fluctuaba entre su casa, el barrio donde están sus vecinas y el manglar. Sin duda allí ha vivido varias experiencias, ha sentido sobre ella el peso de las relaciones de poder y su autorreconocimiento como mujer negra, madre y sujeto político.

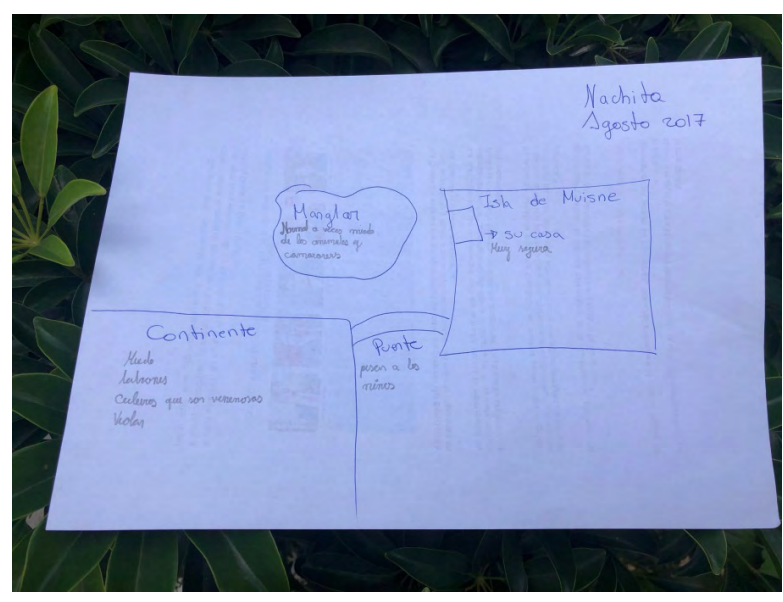

Figura 2. Mapas sobre zonas que Nachita considera seguras en Muisne

Fuente: Archivo personal de la autora.

Oslender (2002) teoriza en referencia a Lefebvre (1991) y menciona la posibilidad de espacializar las resistencias por medio de uno de los tiempos del espacio llamado "espacio de representación", donde se albergan las experiencias del día a día, 
los conocimientos que se han adquirido colectivamente y que se consolidan en una identidad propia en relación con la colectividad, tomando en cuenta que estas construcciones parten de la experiencia, del diario vivir y, por ende, siempre están en movimiento. El espacio de Nachita, entonces, es donde está su memoria, donde ha vivido conflictos y por ende ha ejercido procesos de resistencia. Por eso ha sido tan importante para ella regresar, buscar alternativas, devolverse a su lugar seguro, aunque el Estado o cualquier mirada externa le diga que es justamente allí en donde está el riesgo.

Muisne es mi todo porque aquí yo nací y yo ya sé cómo es el movimiento en mi pueblo. Allá, imagínese, en esa ciudadela uno no tiene esa privacidad, uno no tiene ese espacio [...], arriba me ha tocado el apartamento, pero no puedo tener esa cavidad de lavar mi ropa y tirar mi agua y que se moje porque la vecina de abajo ya se va a sentir mal [...], hay que lavar con cuidado, no hay que hacer bulla, es una cosa como que usted esté privada de su libertad, así es allá (Entrevista con Nachita, octubre de 2018).

\subsection{Volver a casa: entre la} experiencia de perderlo todo y la agencia para regresar al espacio vivido

La mayoría de las personas que sobreviven a una catástrofe de esas características desean precisamente lo contrario de "un nuevo principio".

Quieren salvar todo lo que sea posible y empezar a reconstruir lo que no ha perecido, lo que aún se tiene en pie. Desean reafirmar sus lazos con la tierra y los lugares en los que se han formado.
En mayo de 2017, después de pasar por dos albergues para damnificados, Nachita recibió la casa ofrecida por parte del Gobierno, ubicada a kilómetros de la isla de Muisne. Los primeros días después de la mudanza sintió mucha alegría porque tenía un documento formal que señalaba que el lugar en el que ahora viviría estaba a su nombre. También sintió tranquilidad, pues ya no tendría que recibir órdenes militares como en un cuartel. Sin embargo, la felicidad fue temporal, ella sentía que debía regresar a la isla, al mar, al manglar, a las tardes de conversación con las vecinas en los porches de sus casas sobre sillas plásticas... No tenía dinero para construir de nuevo sobre el estuario puesto que el terremoto la obligó abandonar su oficio de conchera.

No puedo vivir allá porque no tengo una fuente de trabajo y para ir uno allá tiene que tener dinero porque una moto cobra un dólar de allá arriba, [desde] la ciudadela [hasta] acá por cabeza, no por el flete, sino por cabeza; si yo voy con mis hijos tengo que tener tres dólar [sic] solamente de ida y tres dólar de venida, son seis dólar que yo tengo que tener todos los días para ir y venir (Entrevista con Nachita, octubre de 2018).

El proceso de construir y reconstruir después de una catástrofe tiene que ver principalmente con la reorganización del día a día, de las rutinas, de las comidas, de las horas para dormir y levantarse y en este cotidiano las mujeres juegan el rol más importante al hacerse cargo de su familia, de brindarles apoyo emocional, seguridad y buscar alimentos (Pezoa Navarro, 2010). De esta forma se convierten en las principales rehacedoras de los espacios a través de diversas tácticas de resistencia, pero también de agencia personal. 
"Gracias a Dios salí favorecida la primera": Nachita cuenta que se inscribió en un sorteo realizado por una ONG italiana, que no recuerda el nombre y que unos días después le informaron que ganó nada más y nada menos que una casa levantada sobre su antiguo hogar en la isla de Muisne. Le informaron que sería construida con materiales $100 \%$ naturales: dos pisos de bambú, carrizo y barro con la mejor tecnología antisísmica ahora eran para ella y su familia. La alegría no le cabía en el pecho, pasó de quedarse en la calle por el terremoto y la experiencia de sobrevivir dentro de un albergue a tener dos propiedades a su nombre. El regreso de Nachita a su espacio para retomar la cotidianidad, después de una salida forzosa, tiene una base importante en la agencia, es decir, en "la capacidad de llevar a cabo los propios intereses en contra del peso de la costumbre, la tradición, la voluntad trascendental, u otros obstáculos" (Mahmood, 2005, p. 73). Desde el planteamiento de Mahmood (2005), las acciones tomadas fueron cognitivas y emocionales y la llevaron al cumplimiento de objetivos que probablemente no estaban presentes de manera consciente, y de este modo les dio un nuevo significado a las prácticas culturales porque las llevó a su espacio para reconstruirlas.

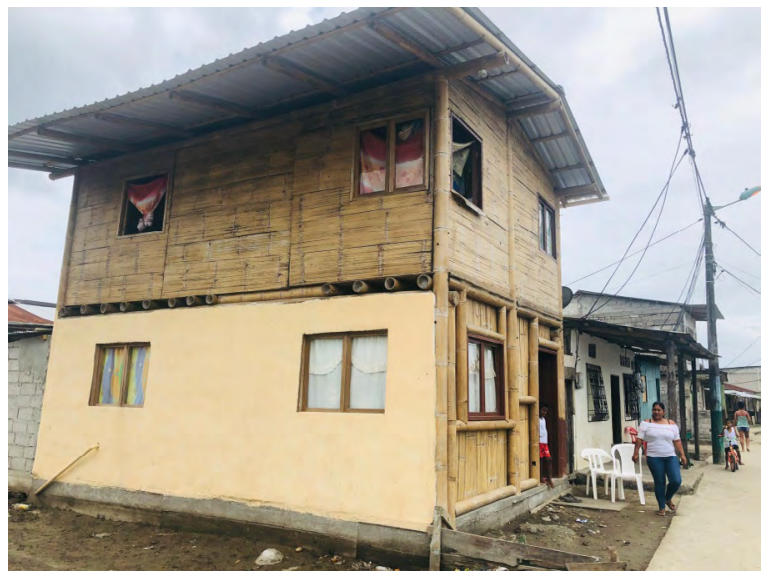

Figura 3. Nachita frente a su casa en octubre de 2018 Fuente: Archivo personal de la autora.

Vol. $25 \mathrm{~N}^{\circ} 2$

julio - diciembre de 2020 pp. $80-101$
En un estudio de Magaña Frade et al. (2010) sobre la intervención psicosocial en comunidades afectadas por terremotos se explica la manera en que las mujeres, de manera inconsciente y siguiendo una matriz de género, ejercen como las principales mediadoras de la reconstrucción y de la recuperación de sus espacios y el de sus familias. A través del concepto de mediadores psicosociales, se refieren a las estrategias de afrontamiento como

[...] el protagonismo femenino en el espacio comunitario, para la reorganización de la vida cotidiana y la reconstrucción; la articulación de la autogestión y el apoyo mutuo; y la mediación con las autoridades e instituciones, en la que quedan ubicadas como las articuladoras entre el espacio público y el privado (p. 175).

Aterrizando el concepto, en el caso específico de Nachita es posible apreciar cómo el amor por su familia, sus prácticas cotidianas en el manglar y la negociación con el Estado por su espacio han sido pilares fundamentales para su proceso de reconstrucción.

Surge así la posibilidad de apropiación de los derechos a través de la organización-reorganización, configuración-reconfiguración, construcción-reconstrucción de las relaciones sociales y de los espacios que significan la vida misma. A partir del planteamiento de Gómez (2012) se sugiere que construir y reconstruir es un acto político para las mujeres, que les brinda la oportunidad de recrear cartografías, mapas, trazos de la memoria y del cuerpo. 


\subsection{El manglar en Muisne: entre la expansión de los paisajes del capital y el espacio íntimo para contar historias y saberes}

\author{
El fogón es tu cocina \\ Tus hijos tu diversión \\ Los montes tu medicina \\ La sombra tu protección \\ Un buen pescao tu comida \\ La chillangua tu sazón \\ Mangle barrera de vida \\ Protegerlo es tu razón \\ Para apurar la comida \\ Leña e mangle tu carbón. \\ LinVer NAZARENo, mujer del manglar
}

Es un día caluroso, 30 grados centígrados marca el termómetro, el sol pega directamente en su cara y en sus manos morenas y fuertes, el resto del cuerpo está cubierto con ropa y botas de caucho. La canoa está lista para zarpar equipada con un remo $\mathrm{y}$ costales para recolectar lo que brinde la naturaleza. Aproximadamente treinta minutos de recorrido por el brazo del mar, pidiendo a Dios que le dé la sabiduría para escoger el mejor sitio, con suficiente concha para sustentar los gastos del día.

Cuando Nachita está en el manglar se mueve con total naturalidad por las ramas, ya no hace tanto calor como en la isla, el entramado hace una sombra natural y confortable. Ella sabe exactamente dónde pisar, escucha atenta el "clic" que hacen las conchas al abrirse y cerrarse, se acerca dando pasos largos, como bailando con el sonido de su sustento. Ella cuida cada detalle, lo hace con amor, con ternura, con cuidado, mete la mano por un huequito y saca una concha grande y negra que va directo al costal, las más pequeñas son devueltas a su origen. Las reglas para conchar no están escritas, no están normadas, es un ejercicio de aprendizaje que se transmite de generación en generación.

Los manglares son árboles y arbustos que crecen a manera de redes sobre los estuarios por donde pasan los ríos de agua dulce antes de desembocar al océano. Al estar en contacto con agua dulce y salada, guardan en sus pantanos una variedad de fauna que ha servido como sustento para poblaciones que históricamente han convivido con ese ecosistema. La formación boscosa del manglar contribuye a la cadena alimentaria marina porque produce detritos, y varias especies de animales marinos de importancia comercial pasan al menos parte de su ciclo vital en ellos. Por eso los manglares no deben considerarse solamente como bosques, sino también como productores de alimentos en forma de cangrejos, peces y camarones, muchos de los cuales terminan por ser capturados lejos de los manglares (Christensen, 1983).

Según el Sistema Nacional de Áreas Protegidas del Ecuador (2019), existen 3.173 hectáreas de manglar protegidas. En el bloque norte se ubica la provincia de Esmeraldas, específicamente San Francisco, Bunche, isla de Muisne, San Gregorio y Bilsa. Sus sistemas radiculares protegen las costas tropicales formando una barrera natural contra aguajes e inundaciones además de constituirse en un albergue de especies marinas y silvestres, pues son el vínculo entre varios ecosistemas (Christensen, 1983).

En el año 2003 el estuario del río Muisne fue declarado refugio de vida silvestre, lo cual implica la prohibición de la tala e incentiva a la conservación y la preservación por parte de las autoridades nacionales, locales y la población que allí reside. Sin embargo, la construcción de piscinas para la 
producción de camarones ha proliferado y las empresas camaroneras, haciendo caso omiso de las reglamentaciones de una reserva natural y con la autorización tácita de los gobiernos de turno, han destruido el $83 \%$ de la extensión original del manglar (Fundación de Defensa Ecológica Ecuador [Fundecol], 2002). Nachita recuerda que veinte años atrás recogía 400 conchas en tan solo media hora. Ahora, con un manglar que desaparece por causa de las camaroneras y el limitado mercado de restaurantes y turismo en Muisne después del terremoto, apenas consigue para comprar arroz y mezclarlo con lo que alcance. Ella necesita 30 dólares diarios para alimentar a sus siete hijos y cinco nietos tres veces al día, además del pago de la tricimoto para llevar a los niños a la escuela y uno que otro implemento de limpieza. Con cuatro horas en el manglar apenas logra conseguir un ciento de conchas que después, corriendo con suerte, será vendido por 10 dólares.

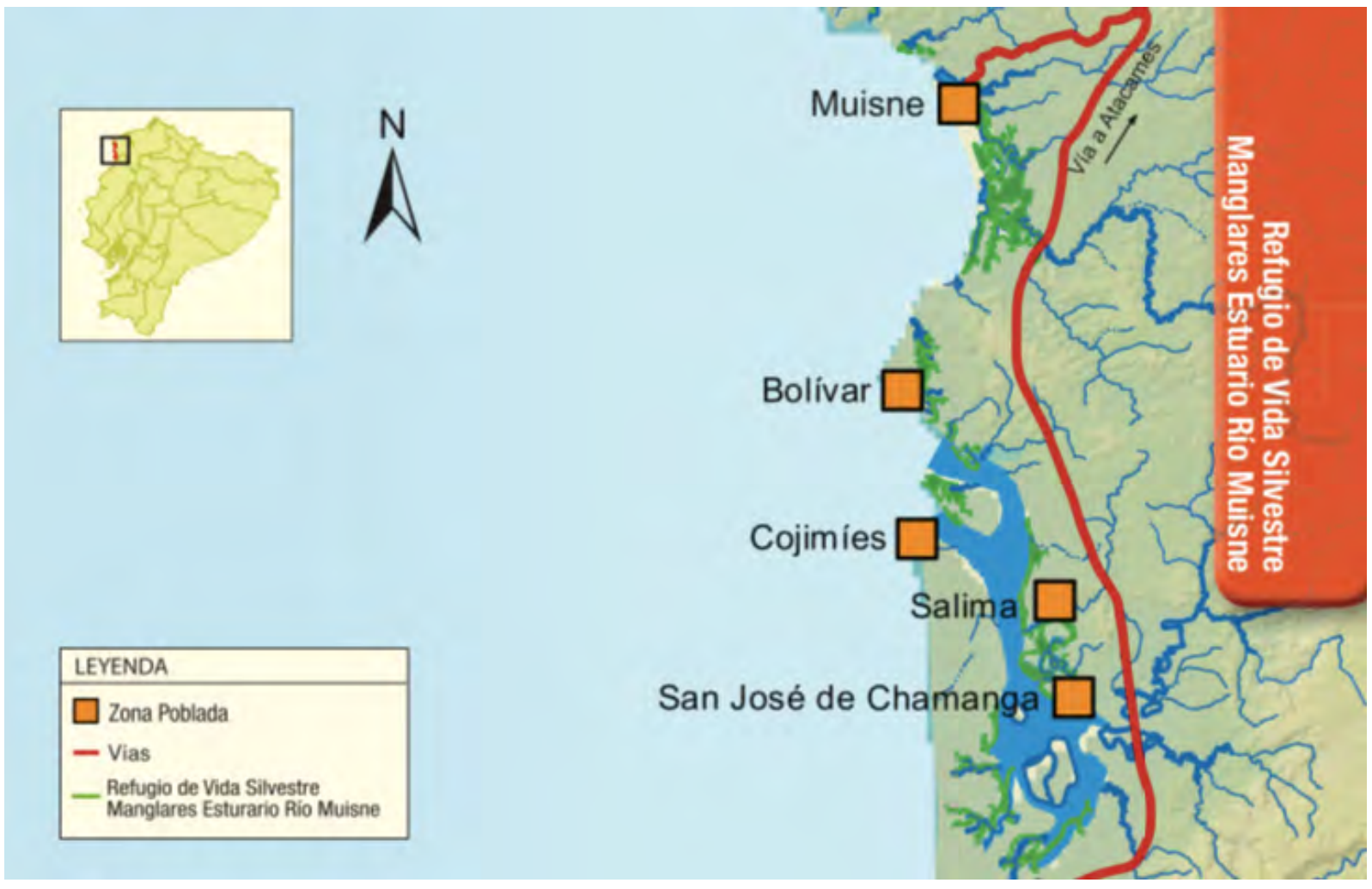

Figura 4. Detalle de los manglares en la costa de Ecuador

Fuente: Sistema Nacional de Áreas Protegidas del Ecuador (2019).

Los cuerpos de las mujeres de Muisne, fuertes, robustos, valientes, son usados por el mercado y explotados con violencia (Monárrez Fragoso, 2006, p. 433). La vinculación especial de Nachita con el manglar, más allá de una plaza de trabajo, es el motor de la reproducción del capital social y económico porque pese a que no son formalmente reconocidas ni remuneradas mantienen la vida de ella y su familia (Benería, 1999, p. 24). 
Sin embargo, desde la investigación de campo se observó también cómo en la práctica las mujeres de Muisne, desde su agencia personal, negocian con el capital y continúan transitando, mapeando $\mathrm{y}$ viviendo del mangle. El ecosistema del manglar está en directa relación con el sistema socioeconómico de las mujeres negras, mestizas e indígenas que, desde sus saberes ancestrales, han vivido de la recolección de las especies que habitan en este entrelazado boscoso (Fundecol, 2003). Ellas valoran este ecosistema, está encarnado en sus cuerpos porque básicamente su vida y la de sus familias dependen de ello. Los seres humanos tenemos maneras particulares de proteger, preservar y vivir con el medio ambiente, y es por ello por lo que comprender las relaciones que se han forjado con el espacio del cual se depende social y económicamente es crucial.

Oslender (2002) utiliza la noción de "espacio acuático" para referirse a la manera en que el agua, desde varias formas y vertientes, ha influido en las formas de vida cotidiana de las poblaciones del Pacífico. Los secretos más íntimos, los sueños, los planes para el futuro, las anécdotas familiares, las recetas, las invitaciones a las fiestas, las noticias de embarazos y los muertos del barrio son aspectos significativos de sus vidas. Alrededor del manglar las mujeres han creado toda una red de apoyo y saberes que además las identifican colectivamente y forman una "estructura acuática de sentimiento [...] que constituye una de las precondiciones espaciales para la organización política" (p. 115).

Las mujeres crean estrategias de defensa del territorio por medio de redes de apoyo en defensa del manglar. También se concentran en su habitar diario, en su transitar para marcar su espacio y dar a entender que eso es de ellas, que fue de sus abuelas y que será de sus hijas si es que ellas así lo quieren. Ulloa (2016, p. 134) ubica esta acción dentro de los feminismos territoriales como "protestas y acciones de mujeres indígenas, afrodescendientes y campesinas en contra de los procesos extractivos que plantean tanto críticas como alternativas a las dinámicas económicas que se derivan de la relación modernidad/colonialidad". En el caso específico de Muisne, ellas se mantienen en permanente lucha desde la cotidianidad, desde la manera en que usan sus cuerpos para defender el manglar. Uso el concepto de Gómez (2012) sobre el cuerpo como territorio político porque es asumido como histórico y no biológico, porque ha sido construido mediante historia y memoria en donde se habita a partir de una reconstrucción, de una decisión para repensarse (p. 6).

Pensemos entonces que las estrategias políticas vinculadas al cuerpo de las mujeres determinan el destino del territorio y de la comunidad por medio de acciones como la trasmisión de saberes y la cotidianidad, so pena de reforzar las diferencias de género y feminizar el cuidado de la naturaleza.

¿Si escucha el sonido que hacen las conchas? Eso, mi preciosa, significa vida, están ahí llamándonos para que las cojamos, para que las hagamos un rico ceviche y nosotras también vivamos. Así funciona esto, por eso cuidamos tanto estas matas porque, aunque nos caigamos, nos ensuciemos, nos quememos y nos pique el pez sapo, de esto vivimos (Nachita Bautista).

\section{Conclusiones}

A raíz del terremoto de 7,8 grados que afectó a las provincias costeras de Manabí y Esmeraldas y, en 
este caso específico de estudio, a la población de Muisne, se evidenció la conexión entre el desastre y los nuevos paisajes del capital que cambian también la geopolítica de los cuerpos sexuados para perpetuarlos como medios de acumulación con un valor de mercancía. El capital, hábilmente $\mathrm{y}$ apoyado por toda una estructura globalizada de consumo en situaciones de desastre, construyó un paisaje geográfico que desplazó a la población, y particularmente a las mujeres, de sus espacios vitales alrededor de la isla, del manglar, de su cotidianidad, de su vida misma.

Las políticas públicas implementadas en Muisne después del terremoto partieron de una lógica estatal de desplazamiento por factores asociados al riesgo y trabajaron en la producción de una isla foco de la inversión privada (las camaroneras) y pública (un puente peatonal que reemplazó a la gabarra) pensando en la modernización, el turismo y las empresas, desdibujando así la ruralidad y colocando al capital sobre el ser humano. La noción de modernización en un contexto globalizado trajo consigo configuraciones de las relaciones de poder y la producción de nuevas diferencias a través del manejo de la población, ligados a determinados intereses de los sectores con mayor poder económico y social, en donde unas vidas tienen más valor que otras, configurando así a sujetos desechables (Mbembe, 2011).

Los pescadores, las concheras, el manglar y las casas de caña se convirtieron en un obstáculo para la modernización de la isla, para el reordenamiento y la creación de nuevos paisajes en un contexto de desastre. Pese al poder estatal y la falta de servicios básicos y de apoyo económico, los muisneños y muisneñas se resistieron al desalojo del territorio porque en él convergen los saberes, la memoria y la pertenencia. Para el caso particular de las mujeres de Muisne, el aferrarse a su espacio a través de estrategias políticas ligadas a sus saberes y sus cuerpos fue la respuesta resiliente para el desastre, aunque siempre ligada a desigualdades previas.

Se concluye entonces que las voces de los y las habitantes de Muisne fueron excluidas a la hora de generar políticas públicas de apoyo para las víctimas del terremoto que sufrió Ecuador en el 2016. Sus sentimientos, su modo de vida, su cultura, tradiciones, anhelos, problemas, miedos y preocupaciones fueron obviados, desconociéndolos así como sujetos participantes y activos de su propia vida e historia. Quedó en evidencia que las acciones tomadas en un contexto de desastre fueron el resultado del abandono previo, del desconocimiento del territorio donde se trabajaba y, sobre todo, del desconocimiento de las características de la población. Las políticas públicas dejaron fuera a las personas y las ubicaron como objetos, mas no como sujetos participantes con derechos y, sobre todo, como dueñas legítimas del territorio. Desconocieron que la isla es el espacio de vida y el sostén de la comunidad de Muisne, que históricamente ha trabajado alrededor del mangle y del mar. El desplazamiento forzado a ciudades de concreto fue un acto violento que causó más depresión en los habitantes que el mismo terremoto. La dinámica de reconstrucción del Estado, aparte de propiciar el desplazamiento, reforzó la dicotomía entre lo público y lo privado, adquiriendo así una gran deuda en cuanto a la generación de políticas públicas con enfoque de género, ya que no se generaron procesos participativos que permitan que las mujeres en su diversidad logren desarrollar sus propias transformaciones y recursos para satisfacer las necesidades propias y las de sus familias. 
Como se planteó en esta investigación, después del terremoto y el desalojo surgieron procesos de resistencia y de apropiación, construcción y reconstrucción de espacios que significaron un renacer en las condiciones de vida, relaciones familiares y agencia personal de las mujeres. A través de estrategias políticas intrínsecas a sus propios cuerpos, memoria y experiencia, se construyeron como cuidadoras de su territorio, de los suyos, de su historia, porque les pertenece más allá de los títulos de propiedad.

Pese a las circunstancias previas al desastre, las mujeres tuvieron la capacidad de resiliencia desafiando y reconfigurando las relaciones cotidianas de género y su dinámica con las estructuras de poder como único modo de supervivencia. Se configuraron resistencias y luchas mediante los espacios y los cuerpos de las mujeres por medio de economías de subsistencia alrededor de los alimentos. Ellas priorizaron la defensa de su espacio como una lucha política, se organizaron para producir vida.

La agencia personal juega un rol muy importante en contextos de desastres, las mujeres tuvieron la posibilidad de recrear sus propias cartografías con las marcas de la memoria y del cuerpo como su propia historia. Así, a más de reconstruir sus hogares, los convirtieron en un espacio de lucha que reconoce emociones y subjetividades para también reconstruir las relaciones de género. Una estrategia para resistir ante las políticas estatales fue la desobediencia de los habitantes de Muisne para no abandonar sus hogares. Armaron vigilias por el cuidado del territorio y mantuvieron vivas las historias del manglar, de las mareas altas y bajas, de la comida, de las palmeras, de las aventuras y desventuras y a un solo grito le dijeron al Estado: "De Muisne no nos vamos, aquí nos quedamos". 


\section{Referencias}

Agamben, G. (1998). Homo Sacer. El poder soberano y la vida nuda. Giulio Einaudi Editore S.P.A.

Arroyo, R. \& Valladares, L. (2005). Derechos humanos y violencia sexual contra las mujeres. En G. Andrade Moncayo (ed.), Violencia sexual contra las mujeres. Proyecto regional Corte Penal Internacional y Justicia de Género, La Morada, Corporación Promoción de la Mujer, Serie Documentos Técnico Jurídicos.

Beck, U. (1998). La sociedad del riesgo: hacia una nueva modernidad. Paidós.

Benería, L. (1999). Mercados globales, género y el hombre de Davos. La Ventana, 1(10), 7-48.

Bernal, G. (Trad.). (1998). "Espacio, lugar y género" de Doreen Massey. Debate Feminista, 17, 39-46.

Blanco, J. (2007) Espacio y territorio: elementos teórico-conceptuales implicados en el análisis geográfico. En C. Fernández \& R. Gurevich (coord.), Geografía. Nuevos temas, nuevas preguntas. Un temario para su enseñanza (pp. 37-64). Biblos.

Borja, J. (2003). La ciudad conquistada. Alianza.

Cabezas, A. \& Berná, D. (2013). Cuerpos, espacios y violencias en los regímenes biopolíticos de la Modernidad. De maricas y homosexuales habitando "Io femenino". Política y Sociedad, 50(3), 771-802.

Castillo, S. F. (2011). Geografía, construcción de territorio y justicia social: prácticas espaciales, género y desarrollo en Chile. Revista Geográfica de América Central, 2(47E), 1-11. https://www.revistas.una.ac.cr/index.php/geografica/article/ view/2779.

Castro-Gómez, S. (2000). Ciencias sociales, violencia epistémica y el problema de la "invención del otro". En E. Lander (comp.), La colonialidad del saber: eurocentrismo y ciencias sociales. Perspectivas latinoamericanas (pp. 88-98). Consejo Latinoamericano de Ciencias Sociales (Clacso).

Christensen, B. (1983). Los manglares ¿para qué sirven? http://www.fao.org/3/q1093s/ q1093s01.htm.

Comisión Económica para América Latina y el Caribe (Cepal), Observatorio de Igualdad de Género de América Latina y el Caribe. (2012). Informe anual 2012: los bonos en la mira, aporte y carga para las mujeres. Cepal.

Deere, C. D. \& León, M. (2002 [2001]). “La importancia del género y la propiedad”, en C. Deere \& M. León, Género, propiedad y empoderamiento: tierra, Estado y mercado en América Latina (2ª ed., pp. 1-44). PUEG y Flacso.

Foucault, M. (1998). Derecho de muerte y poder sobre la vida. En Historia de la sexualidad I. La voluntad de saber (pp. 161-194). Siglo XXI. 
Fundación de Defensa Ecológica Ecuador (Fundecol). (2003). Plan de manejo preliminar del Refugio de Vida Silvestre del ecosistema manglar del estuario del río Muisne en el sistema Muisne-Cojimíes y su área de influencia. Quito, Ecuador.

Fundación de Defensa Ecológica Ecuador (Fundecol). (2002). Estudio de alternativas de manejo del estuario de manglares del río Muisne entre el sistema Muisne-Cojimíes. Quito, Ecuador.

García Acosta, V. (2004). La perspectiva histórica en la antropología del riesgo y del desastre. Acercamientos metodológicos. Relaciones. Estudios de historia y sociedad, 25(97), 124-142.

Horton, L. (2015). Disaster through a gender lens: A case study from Haiti. En R. Dahlberg, O. Rubin \& M. T. Vendelø (eds.), Disaster research: Multidisciplinary and international perspectives (pp. 140-156). Routledge.

Instituto Nacional de Estadística y Censos (INEC). (2010). Censo de Población y Vivienda 2010. http://www.ecuadorencifras.gob.ec/base-de-datos-censo-de-poblacion-yvivienda/.

Klein, N. (2008). La doctrina del shock. El auge del capitalismo del desastre (1 $1^{\mathrm{a}}$ ed.). Paidós. http://www.katari.org/pdf/shock.pdf.

Lefebvre, H. (1991 [1974). The production of space. Blackwell.

Luft, R. (2009). Beyond Disaster Exceptionalism: Social Movement Developments in New Orleans after Hurricane Katrina. From American Qurterly, 61(3), 499-527.

Magaña Frade, I., Silva-Nadales, S. \& Rovira, R. (2010). Catástrofe, subjetividad femenina y reconstrucción: aportes y desafíos desde un enfoque de género para la intervención psicosocial en comunidades afectadas por el terremoto. Terapia Psicológica, 28(2), 169-177.

Mahmood, S. (2005). The Subject of Freedom. En Politics of Piety. The Islamic Revival and the Feminist Subject (pp. 1-39). Princeton University Press.

Malo, M. (Ed.) (2004). De preguntas, ilusiones, enjambres y desiertos. Apuntes sobre investigación y militancia desde Precarias a la deriva. En Nociones comunes. Experiencias y ensayos entre investigación y militancia (pp. 81-92). Traficantes de Sueños. https://www.traficantes.net/sites/default/files/pdfs/Nociones\%20comunesTdS.pdf

Massey, D. (1999). La filosofía y la política de la espacialidad: algunas consideraciones. En L. Arfuch (comp.), Pensar este tiempo. Espacios, afectos y pertenencias (pp. 101-128). Paidós.

Massey, D. (1985). "New Directions in Space", en D. Gregory y J.Urry (eds.), Social Relations and Spatial Structures (pp. 9-19). Macmillan.

Mbembe, A. (2011). Necropolítica y Sobre el gobierno privado indirecto. Melusina.

McDowell, L. (2000). Cap. 2. Dentro y fuera del lugar. Cuerpo y corporeidad. En: Género, identidad y lugar. Un estudio de las geografías feministas (pp. 11-35). Cátedra.

Monárrez Fragoso, J. (2006). Las víctimas del feminicidio juarense: mercancías sexualmente fetichizadas. Fermetum, 16(46), 429-445. 
Oslender, U. (2002) Espacio, lugar y movimientos sociales: hacia una "espacialidad de resistencia". Scripta Nova, Revista Electrónica de Geografía y Ciencias Sociales, 6(115).

Pezoa Navarro, R. (2010). Mujeres: ojo con los mensajes de reconstrucción. http:// www.observatoriogeneroyliderazgo.cl/index.php?option=com_contenttas\%20 $\mathrm{k}=$ viewid=2697 Itemid $=2$.

Rodó de Zárate, M. (2014). Developing geographies of intersectionality with Relief Maps: reflections from youth research in Manresa, Catalonia. Gender, Place \& Culture, 21(8), 925-944.

Sassen, S. (2006). Hacia una proliferación de ensamblajes especializados de territorio, autoridad y derechos. Cuadernos del Cendes, 23(62), 95-112.

Secretaría de Gestión de Riesgos. (2016). Resolución n SGR-073-2016. http://www. gestionderiesgos.gob.ec/wp-content/uploads/downloads/2016/07/Resolucion-No.SGR-073-2016.pdf.

Secretaría de Planificación y Desarrollo \& Comisión Económica para América Latina y el Caribe (2016). Evaluación de los costos de reconstrucción. Sismo en Ecuador. Abril 2016. https://www.planificacion.gob.ec/wp-content/uploads/downloads/2016/08/ Evaluacion-de-los-Costos-de-Reconstruccion-Resumen-Ejecutivo.pdf.

Sistema Nacional de Áreas Protegidas del Ecuador. (2019). Manglares estuario río Muisne. http://areasprotegidas.ambiente.gob.ec/es/areas-protegidas/refugio-de-vidasilvestre-manglar-el-estuario-del-r\%C3\%ADo-muisne.

Secretaría Nacional de Planificación y Desarrollo. (2013). Atlas de las desigualdades socio-económicas del Ecuador. Secretaría Nacional de Planificación y Desarrollo. https://www.planificacion.gob.ec/atlas-de-las-desigualdades-socio-economicas-seconvierte-en-un-referente-para-la-gestion-del-estado/.

Tele Ciudadana. (20 de agosto de 2016). Enlace Ciudadano 489 desde Playa las Palmas, Esmeraldas. [Video]. https://www.youtube.com/watch?v=cg-qVd6-wH4.

Ulloa, A. (2016). Feminismos territoriales en América Latina: defensas de la vida frente a los extractivismos. Nómadas, 45, 123-139. 